\title{
Resenha
}

\section{A marxologia vive em 0 velho Marx: por que ler Marx 200 anos depois do seu nascimento?}

Murilo Leite Pereira ${ }^{1}$

MUSTO, Marcello. O velho Marx: uma biografia de seus últimos anos (1881-1883). Trad. Rubens Enderle. São Paulo: Boitempo, 2018. 158p.

Na aula inaugural da cadeira de antropologia social, ministrada no Collège de France, em 5 de março de 1960, C. Lévi-Strauss aludiu à mística do número oito, “já ilustrad[a] pela aritmética de Pitágoras, pela tabela periódica dos corpos químicos e pela lei de simetria dos polvos" (LÉVISTRAUSS, 2017, p. 11), para relacionar uma série de eventos caros à sua disciplina ${ }^{2}$. À lembrança do antropólogo francês, não teríamos como iniciar nossa resenha da obra de Marcello Musto, O velho Marx: uma biografia de seus últimos anos (1881-1883), sem antes mencionar o retorno místico do oito neste ano, que coleciona uma quantidade significativa de efemérides importantes para a história mundial e nacional, as quais se não servem aos mais céticos para confirmar a magia do aludido número também não a negam.

Comemoramos o bicentenário do nascimento de Karl Marx, 170 anos das vulcânicas Revoluções de 1848, a chamada primavera dos povos, e há 50 anos o mundo vivia as turbulências de 1968, cujo símbolo mais lembrado é o Maio de 68 francês, cenário no qual foi escrita uma das obras de maior repercussão do marxismo no século $\mathrm{XX}, \mathrm{O}$ direito à cidade, de Henri Lefebvre. No Brasil, nesse mesmo ano, assistimos ao recrudescimento da ditadura civil-militar por meio do Ato Institucional n. 5 (AI-5). Não é só. Em 2018 também comemoramos o centenário de nascimento do maior crítico literário brasileiro e um dos nossos mais importantes intelectuais socialistas, Antonio Candido. A lista, como se vê, é, além de diversa, quase infindável.

\footnotetext{
1 Mestre e doutorando pela Universidade Federal de Minas Gerais (UFMG). E-mail: murilo.leite.pereira@gmail.com.

2 Em 1958, criou-se no Collège de France a cadeira de antropologia social; em 1908, Sir J ames George Frazer proferira na Universidade de Liverpool a aula inaugural da primeira disciplina criada no mundo com o nome de antropologia social; 50 anos antes, em 1858, nasciam dois dos principais mestres da futura disciplina, Franz Boas e Émile Durkheim (LÉVI-STRAUSS, 2017, pp. 11-3).
} 
Há exatamente uma década vivemos os efeitos sociais, econômicos e políticos da crise de 2008, que, como todo evento histórico de grandes proporções, não foi sentida igualmente e no mesmo tempo em todas as partes do mundo. É provável que também aqui o desenvolvimento desigual e combinado - o qual, como alerta Musto (2018a, pp. 81-3), fora pelo menos esboçado por Marx $^{3}$ nos debates com os então chamados populistas russos - tenha atuado pegando de surpresa os mais habilidosos políticos ${ }^{4}$, cujas crenças "politicistas"5, quase tão fantásticas quanto a mística do oito, têm nos distanciado dia após dia da emancipação humana geral. Essa década pós-crise de 2008 também marcou o ressurgimento, segundo Musto (2018a, p. 10), do interesse pela obra de Marx ${ }^{6}$, o que coincidiu com a retomada do projeto MEGA, hoje, chamada MEGA2, e suas descobertas ${ }^{7}$.

Ler Marx: tarefa relativamente fácil nos nossos dias. Basta observarmos a crescente quantidade de boas traduções realizadas de suas obras (e também das de Engels) nas últimas duas décadas para o nosso idioma. Aqueles que leem em inglês podem ainda encontrar, por exemplo, numa simples busca no Google, sem que seja preciso sair de casa ou de onde quer que esteja, as edições completas dos Collected works de Marx e Engels, 50 volumes para o deleite do leitor. Aos familiarizados com a

\footnotetext{
3 Marx "negou (...) a necessidade histórica do desenvolvimento do modo de produção capitalista em todas as partes do mundo" (MUSTO, 2018a, p. 81), abrindo caminho para "um verdadeiro internacionalismo em escala global, não mais apenas europeia" (MUSTO, 2018a, p. 83). Desse modo, expôs sua "concepção multilinear" que se atém, sobretudo, às especificidades históricas, considerando a possibilidade do "desenvolvimento desigual das condições políticas e econômicas entre países e contextos sociais diferentes" (MUSTO, 2018a, p. 83).

4 Um bom exemplar do politicismo brasileiro pode ser retirado da entrevista do então presidente da República Luís Inácio Lula da Silva. Em 4 de outubro de 2008, ele declarou que a crise chegaria ao Brasil, caso realmente chegasse, como uma "marolinha", embora ele mesmo tenha reconhecido a força avassaladora da crise nos Estados Unidos da América (GALHARDO, 2018).

5 Para maiores aprofundamentos acerca desse ponto, é incontornável a leitura de Chasin (1999; 2000).

${ }^{6}$ Em 30 de março de 2014, The New York Times lançou um debate chamado "Was Marx right? (THE NEW YORK TIMES, 2018). Antes disso, em 2011, Terry Eagleton (2011), imbuído de semelhante espírito, lançou a sua obra Why Marx was right. Não se pode esquecer da obra de Thomas Piketty, Le capital au XXIe siècle, publicada em 2013 na França, cuja proposta explícita foi desabilitar uma leitura contemporânea de O capital, obra-prima inacabada de Marx. Cinco anos depois de seu lançamento na França, o livro de Piketty se mostrou ultrapassado na proposta conciliatória e insuficiente na análise.

7 O próprio Musto (2018a, p. 10) nos conta em seu livro que desde 1998 já foram publicados 26 novos volumes das obras completas de Marx e Engels, os quais se somam aos 40 volumes publicados entre 1975 e 1989. Para mais esclarecimentos acerca da história das publicações das obras de Marx e Engels, cf. Hobsbawm (1983, pp. 423-43) e Cerqueira (2015, pp. 825-44). Já para se inteirar dos novos percursos e diretrizes de publicação da MEGA2, cf. Hubmann (2012, pp. 33-49). Por fim, não poderia ser diferente, para visões mais críticas do projeto MEGA-2, cf. Martins (2013, pp. 135-43) e Marxhausen (2014, pp. 95-124).
} 
língua alemã, o horizonte de leitura é certamente ainda mais amplo tornou-se frequente a publicação de textos inéditos de Marx, na maioria dos casos, rascunhos, já que a proposta é editar, seguindo critérios histórico-críticos ${ }^{9}$, com o mínimo de modificação possível, todos os escritos de Marx e Engels. Tendo isso em conta, sem dúvida, um dos principais méritos da obra de Marcello Musto, lançada no Brasil pela Boitempo Editorial e traduzida por Rubens Enderle ${ }^{10}$, é ser um grande chamado à leitura do próprio Marx, além de constituir uma obra esclarecedora e atualizada acerca dos últimos anos do teórico e revolucionário alemão ${ }^{11}$.

É exatamente por esse caminho que gostaríamos de seguir nesse breve texto, ressaltando o auxílio que a obra de Musto fornece para uma leitura mais rigorosa - não apenas dos últimos escritos de Marx - do conjunto da arquitetura intelectual do autor alemão ${ }^{12}$. Quanto a isso, parece sintomático que, ao ser entrevistado por Musto, I. Wallerstein tenha escolhido ressaltar nada menos que a necessidade de ler Marx, o próprio, sem escambos, como diz enfaticamente: "A primeira coisa que tenho a dizer aos jovens é que eles precisam lê-lo" e que "vale muito a pena

8 Aos desejosos de acompanhar o processo de publicação das obras completas de Marx e Engels, bem como os debates em torno do projeto MEGA2 e das obras dos autores alemães, um bom começo é conferir os anuários (Marx-Engels-J ahrbuch) que tratam do assunto, publicados pelos envolvidos com as novas edições e pesquisadores convidados (cf. <http:// mega.bbaw.de/ begleitende-publikationen>).

${ }^{9}$ Michael Heinrich (2018, p. 30), na nota 26 do seu livro Karl Marx e o nascimento da sociedade moderna, recém-publicado no Brasil, diz que "a MEGA[2] segue princípios histórico-críticos: todos os textos serão publicados integralmente, fiéis ao original e com todas as variações (no caso de textos impressos, com as diferenças entre as edições individuais; no caso de manuscritos, com supressões, substituições e alterações). As intervenções dos editores se reduzem ao mínimo necessário e são rigorosamente registradas. Além do texto em si, há um aparato crítico contendo suas variações, notas explanatórias, índice remissivo, uma descrição precisa dos manuscritos, assim como do surgimento e da tradição do respectivo texto. A MEGA[2] está estruturada em quatro seções: I. Obras (sem O capital), II. O capital e trabalhos preparatórios, III. Cartas (contém não somente as cartas de mas também as cartas a Marx e Engels), IV. Excertos (trechos de livros que com frequência contêm notas e comentários)".

10 O título original da obra é: L'ultimo Marx (1881-1883). Saggio di biografia intelletualle.

11 Esclarecemos que essa não é a primeira obra publicada no Brasil que versa sobre os últimos anos de Marx, já que recentemente a editora Expressão Popular verteu para o nosso idioma a clássica obra escrita e organizada por Teodor Shanin (2017); há também o livro organizado por Rubem César Fernandes (1982) na década de 1980, Dilemas do socialismo: a controvérsia entre Marx, Engels e os populistas russos. Contudo, nenhum desses livros constitui uma biografia intelectual dos anos de 1881-1883, não sendo, portanto, focalizada a relação vida e obra, assim como também não contemplam a amplidão temática alcançada pela obra de Musto, a qual vai muito além dos debates havidos entre Marx e os militantes russos. E ainda: tanto Shanin quanto Rubem César Fernandes publicaram antes da retomada do projeto MEGA, no final da década de 1980.

12 Ao leitor interessado noutros enfoques, indicamos a também resenha de Lucas Parreira Álvares (2018), cujo destaque ficou por conta dos diálogos entre Marx e os populistas russos, bem como no modo pelo qual Marx estudou e assimilou as descobertas antropológicas de sua época. 
descobrir Marx, mas é preciso ler, ler, lê-lo. Leiam Karl Marx!” (WALLERSTEIN, 2018). Nesse sentido, não parece ser nenhum acaso que em sua "biografia intelectual" do "último Marx" Musto opte por finalizá-la com um texto de caráter político escrito por Marx, Lafargue e Jules Guesde, o Programa eleitoral dos trabalhadores socialistas, presente no apêndice intitulado "Pelo pão e pelas rosas" (MUSTO, 2018a, pp. 137-41).

Não é pretensão do autor italiano - radicado em Toronto, no Canadá, onde leciona teoria sociológica na York University - substituir a leitura dos escritos marxianos. Na verdade, sua obra desponta como um auxílio às vindouras exegeses, para as quais abre novos caminhos analíticos, agregando-se criticamente à tradição. O marxista italiano acredita que "a renovação da exegese da obra de Marx é um fenômeno destinado a continuar" (MUSTO, 2018a, p. 10), ainda mais se temos em conta que a obra completa do Mouro ${ }^{13}$, o que inclui cartas e cadernos de rascunho, além das obras publicadas ao longo de sua vida, ainda não estão disponíveis ao grande público; muitos dos textos de Marx, como avalia Musto (2018a, p. 10), encontram-se acessíveis apenas "a um círculo restrito de acadêmicos". Assim sendo, por mais brilhantes que sejam os trabalhos que remetem ao itinerário intelectual marxiano, não se pode perder de vista a incompletude do trajeto ${ }^{14}$. Musto, ciente disso, promete reforçar seu projeto renovador com um segundo livro "exclusivamente teórico" que também "se concentrará (...) no derradeiro período de sua elaboração teórica, [d]o assim chamado 'último Marx"” (MUSTO, 2018, p. 10). Quanto a este, aguardemos.

Essa renovação, segundo nosso autor, passará necessariamente, portanto, pela reelaboração biográfica e teórica dos últimos anos da produção intelectual de Marx, período no qual trabalhou incansavelmente, redigindo "cadernos de apontamentos e sínteses de uma quantidade enorme de volumes de matemática, fisiologia, geologia, mineralogia, agronomia, química e física" (MUSTO, 2018a, p. 25). Apesar da coleção de

13 Como explica Musto (2018a, p. 97), esse "era o modo como Marx era chamado em família e pelos companheiros de luta mais próximos". Ainda sobre o apelido de "Mouro", especificamente sobre a tradução da palavra alemã Mohr, citamos a nota à tradução do livro de Michael Heinrich, Karl Marx e o nascimento da sociedade moderna, na qual lemos: "Algumas traduções brasileiras utilizam o termo "mouro", que, traduzido para o alemão, resultaria em Maure, não em Mohr. Na Idade Média, Mohr ainda era utilizado para designar os habitantes do Norte da África, mas, desde o século XVI, o termo é utilizado de maneira generalizada para designar uma pessoa de pele escura." (Cf. MUSTO, 2018a, nota 44)

14 Isso se aplica, inclusive, ao grande e ambicioso trabalho de J osé Chasin (2009), Marx: estatuto ontológico e resolução metodológica, o qual repercute até nossos dias em forma de projetos de pesquisas dos seus orientandos e dos orientados desses últimos, para quem aquele trabalho é um valioso indicativo de rota. Antes, é preciso dizer que a obra de Chasin foi interrompida pelo seu falecimento prematuro, no auge do seu vigor intelectual. 
doenças $^{15}$ que acumulou ao longo da vida, de inúmeros distúrbios familiares $^{16}$ e viagens ${ }^{17}$ para tratamentos diversos que o faziam desperdiçar tempo valioso de estudo e escrita, Marx se manteve atento às mais diversas evoluções e desenvolvimentos da ciência de seu tempo, além de continuar com o projeto de publicação dos livros II e III da sua grande obra, O capital, e estabelecer contato direto com militantes políticos e teóricos de várias partes do globo. Tudo isso contesta a imagem do velhinho que "teria perdido a curiosidade intelectual e a capacidade de elaboração teórica", pelo contrário, "Marx não só continuou suas pesquisas, como estendeu a novas disciplinas" (MUSTO, 2018a, p. 30).

Em outros textos biográficos, cuja pretensão de acabamento definitivo se entrega, sem resistência, a certa linearidade e teleologia, representada pela sucessão de dados e suas respectivas datas, a narrativa constrói um sistema fechado de causas e efeitos, no qual o biógrafo procura a todo instante o sentido da vida do biografado - e talvez esse seja o mérito e o vício do gênero. Ao contrário, O velho Marx, embora não fuja em alguns aspectos à forma (os capítulos, são três, seguem a sucessão do último triênio da vida de Marx), é enriquecido pelo fato de a exposição assumir o inacabamento do seu conteúdo ou de suas análises. Inacabamento que ocorre por diversos motivos: como já dissemos, ainda não conhecemos tudo que é possível conhecer sobre e de Marx, há simplesmente textos seus que não foram publicados, inéditos, portanto; há também várias cartas de cunho pessoal que foram destruídas após sua morte e textos que o próprio autor descartara ao longo da vida. Além

15 Essas não foram poucas. Realizando uma recuperação das que aparecem na obra de Musto, sempre com o risco de alguma patologia ter-nos escapado, chegamos à seguinte listagem, incluindo-se os diversos mal-estares: furúnculos, carbúnculos e erupção de bolhas no corpo, pleurite, tosse quase constante, calafrios, reumatismo, que lhe causou enrijecimento de uma das pernas, resfriados recorrentes, bronquite crônica, hemorragias e abcesso pulmonar, que acabou fazendo com que Marx usasse respirador, o qual ele comparava a uma focinheira.

16 Como as doenças de sua esposa J enny von Westphalen, invadida por um câncer de fígado, que a separou definitivamente de Marx em 2 de dezembro de 1881, quando, "pela primeira vez, desde 1836, quando se apaixonara por ela com apenas 18 anos, ele se viu sozinho" (MUSTO, 2018a, p. 103). Além disso, outro grande abalo foi a doença e posterior falecimento, causado por um câncer na bexiga, em 11 de janeiro de 1883, antes dos 39 anos, da sua filha mais velha, com quem trocara inúmeras cartas. Reagindo à morbidez que também marcam seus últimos anos, as últimas palavras de Marx deixadas sobre um papel, transcritas por Musto (2018a, p. 131) e que demonstram a resiliência do seu caráter, foram as seguintes: "Encontro um pouco de alívio numa horrível dor de cabeça. A dor física é o único 'torpor' da dor mental". Contabilize-se ainda o estado doentio da sua filha Eleanor (MUSTO, 2018a, p. 100), do seu genro Charles Longuet e de seu neto Harry, além da constante imposição de isolamento (MUSTO, 2018a, p. 101), o que acabou impedindo a sua ida ao funeral da sua companheira.

17 Recorrendo uma vez mais à listagem, retirada da leitura da obra de Musto, temos: Londres, Eastbourne, ilha de Wight, Argenteuil, Paris, Marselha e Argel, onde esteve durante 72 dias. Retornando da Argélia, Marx ainda passou, devido a complicações no seu estado de saúde, por Mônaco e Cannes. 
desses motivos mais evidentes, existe um que toca o próprio estatuto teórico do texto biográfico, isto é, que passa pelo reconhecimento do mito da biografia definitiva, que nem de perto é pretensão de Marcello Musto realizar. Este derradeiro motivo inviabiliza de uma vez por todas qualquer desejo de escrita final no campo da produção biográfica, seja quem for o biografado. Como bem destacou Michael Heinrich (2018, p. 319), "uma biografia final de Marx nunca v[ai] existir", pois "cada geração desenvolverá, a partir das condições históricas transformadas, uma nova perspectiva em relação à vida e à obra dele" conduzindo "ao aparecimento de novas biografias". A melhor biografia é sempre aquela que é possível ser escrita nas melhores condições fornecidas por determinada época, o que passa necessariamente pelo acesso às fontes e ainda mais por uma análise crítica delas.

Nesse sentido, a biografia intelectual do "último Marx" escrita por Marcello Musto está em completo acordo com a proposta de diretrizes para a escrita biográfica lançada por Michael Heinrich. Este, partindo da crítica à "escrita biográfica tradicional", cuja base filosófica é o historicismo, sinteticamente, propõe quatro pilares para uma nova forma de biografar (HEINRICH, 2018, pp. 405-6): I) o biografado deve ser retratado como um sistema aberto e encarado sempre na sua relação com a sociedade; II) o "dar sentido" que se procura sempre no texto biográfico deverá ser buscado como "resultado de um processo de comunicação", no qual se coloca como fundamental a "análise precisa das condições desse processo de comunicação", em que a "empatia" e a "revivência" cedem lugar para a explicitação e análise crítica das fontes; III) em vez de a exposição procurar a todo custo sugerir um desenvolvimento teleológico, no qual tudo que ocorreu na vida do biografado teria necessariamente de acontecer, o biógrafo deve procurar na forma expositiva apreender as rupturas e possíveis mudanças de posição, expondo, até mesmo, as lacunas; IV) por fim, o biógrafo deve assumir sua perspectiva, negando qualquer possibilidade de se tornar um narrador onisciente, distanciandose, assim, cada vez mais da biografia ficcional ${ }^{18}$.

O seguimento dessas diretrizes fez de O velho Marx uma provocação à leitura do autor alemão, afinal, lacunas há, ambiguidades também, algumas mudanças de posição, novas aquisições intelectuais foram feitas nesse período e novos enfoques para antigos problemas começaram a ser esboçados; nada disso fica implícito no livro de Musto, o qual nos leva a "duvidar de tudo"19, aproximando-nos o mais possível de

18 Para maiores aprofundamentos acerca dessa questão e dos desafios de biografar Marx, cf. As possibilidades da escrita biográfica hoje: sobre a metodologia em uma biografia de Marx (HEINRICH, 2018, pp. 399-419).

19 Segundo Musto (2018a, p. 84), "durante toda a vida, Marx permaneceu fiel a seu mote preferido: 'De omnibus dubitandum' [é preciso duvidar de tudo]". 
uma posição marxiana, e, desse modo, só há uma postura desejada: retomar a leitura do próprio Marx. Algo que nem sempre foi seguido pelos assim chamados marxistas, situação que foi intuída quase como um presságio pelo próprio Marx, quando fez a famosa afirmação, não sem um toque de humor irônico: "Tudo o que sei é que não sou marxista"20. Sobre isso, é interessante o que nos escreve ironicamente Teodor Shanin (2017, p. 50), para quem, "já na geração de Marx, havia marxistas que sabiam mais que Marx o que era o marxismo e estavam preparados para lhe censurar às escondidas para seu próprio bem"; nem sequer Engels escapou da censura dos doutos marxistas. Bom exemplo disso foi a polêmica que se criou em torno da "Introdução" (ENGELS, 1986) escrita por este último em 1895 para os escritos de Marx (1986) sobre a Revolução de 1848 na França. O texto engelsiano, o último escrito pelo autor, foi em parte censurado pelo Partido Social-Democrata Alemão (SPD), que retirou os trechos nos quais Engels avaliava as potencialidades dos "meios violentos da ação operária", o que transformou o texto numa defesa tout court da via parlamentar. Sobre a reação de Engels, conta-nos Antonio Roberto Bertelli (1986, p. 11):

\begin{abstract}
Ao ver sua "Introdução" publicada com mutilações, fazendo dele um paladino da via parlamentar e pacífica, Engels reagiu energicamente contra a direção e exigiu que a "Introdução" fosse publicada na íntegra. Novamente a direção do partido não ouviu seu pedido e outra vez publicou o texto mutilado, agora em Die Neue Zeit. Engels insistiu, escreveu cartas, mas morreu, em agosto de 1895, sem ver atendido seu pedido.
\end{abstract}

É para uma leitura mais rigorosa que aponta a obra de Musto. Em seu livro, foi capaz de considerar, despido do apego apaixonado à tradição, as biografias de Marx e seus intérpretes mais conhecidos, o cânone por assim dizer, sem abrir mão dos novos ditames de leitura da obra marxiana, bem como das descobertas mais recentes na área da marxologia. O velho Marx é uma obra inovadora também por lançar novos enfoques à vida e obra de Marx, uma vez que contorna "uma figura completamente diferente da esfinge granítica de Marx colocada no centro das praças pelos regimes do Leste europeu, que indicava o futuro com certeza dogmática”. Na verdade, da leitura de Musto o que vem "à tona [é] o Marx de que mais necessitamos: aquele que foi constantemente guiado pelo espírito crítico" (MUSTO, 2018a, p. 11).

Assim orientados por Musto, cuja presença se faz notar a todo momento, como um guia cuidadoso e bem informado dos riscos do trajeto, findamos o mergulho no mar revoltoso ${ }^{21}$ da vida e obra do "Mouro" ou,

20 Sobre esse ponto específico, ver Musto (2018a, pp. 126 ss).

21 Quase tão revoltoso quanto aquele oceano que ele enfrentara para entregar em mãos do editor "a extensa segunda parte do manuscrito" do Livro I de O capital: crítica da 
para os mais íntimos, "Velho Nick"22, tomados por muitos conhecimentos: dos problemas de saúde que impediram Marx de finalizar vários dos seus projetos e que acometeram sua esposa J enny e suas filhas, da lista sem fim de médicos e viagens para tratamentos, somente proporcionais à quantidade de doenças que foram se acumulando no seu corpo; conhecemos ainda mais o seu inesgotável interesse por aprender algo novo, sempre duvidando de tudo e movendo-se nas pesquisas como um "vigoroso andarilho" (MARX, 1968, p. 9) à procura da "lógica da coisa" toda (MARX, 2010, p. 39 ), ainda que isso lhe conduzisse à necessária autocrítica e aos atritos com autointitulados marxistas da época, com os quais o próprio Marx não se identificava. Desse modo, nos últimos anos de sua vida, acabou estudando de maneira sistemática antropologia, história da propriedade, das formações pré-capitalistas e história mundial (MUSTO, 2018a, p. 106), afora matemática pura, por exemplo. Marx também continuou se aprofundando na chamada questão russa, principalmente a partir do diálogo epistolar com Vera Zasulitch, e em outras questões de matéria internacional, pois, como destacou Musto (2018a, pp. 44-77) , Marx se dizia “cidadão do mundo", portanto, atuava onde quer que estivesse, e para isso se mantinha informado dos principais acontecimentos, seja lendo os mais importantes periódicos burgueses e operários ou debatendo com militantes e lideranças políticas do movimento socialista ${ }^{23}$.

A complexidade de Marx, sempre contrário às "fórmulas gerais", énos revelada na exposição do caráter fragmentário e inacabado de sua produção intelectual, por isso, não se encontra nessa biografia uma imagem pronta e acabada, feita sob medida para o altar da revolução. Distante da hagiografia tanto quanto de um banco dos réus, a obra de Musto também não procura condenar nem absolver Marx de coisa alguma, antes, constitui um instigante esboço crítico dos seus últimos anos. É interesse do autor apreender, quando possível, as motivações de certas posições tomadas pelo revolucionário alemão, nesse caso, vida e obra são tomadas em conjunto, como é próprio de uma biografia intelectual. No

economia política. Como assegura Michael Heinrich (2018, p. 16), "ele poderia têlo enviado por correio marítimo, como havia feito, alguns meses antes, com a primeira parte desse manuscrito, mas a questão lhe era importante demais". Para mais detalhes dessa travessia que durou dois dias, cf. Heinrich (2018, pp. 15-8).

22 Segundo Musto (2018a, p. 98), "com esse cognome - Old Nick, que na gíria inglesa significava 'velho diabo' - , ele costumava assinar, sobretudo nos últimos anos de vida, as cartas endereçadas às filhas, a Engels e a Paul Lafargue". Para outros detalhes, cf. nota 52 de Musto (2018a).

23 Um aspecto interessante da biografia de Marx, contado por Musto (2018a, p. 15), é que, com a derrota dos movimentos revolucionários de 1848, "Marx se tornará apátrida" e que, em 1874, teve negado seu pedido de naturalização inglesa, por ser considerado um agitador. 
caso de Marx, como destaca Michael Heinrich (2018, p. 412), isso é ainda mais valioso, pois:

Vários aspectos de sua vida não são compreensíveis sem uma análise do desenvolvimento de sua obra. Em contrapartida, tampouco é possível entender em sua completude as recorrentes interrupções e novas abordagens no desenvolvimento de sua obra sem levar em conta as viradas na vida de Marx.

Inseparáveis do grande intelectual e revolucionário comprometido pelo dever ético de preparar o terreno para a revolução comunista, isto é, da figura pública de Marx, são, portanto, o marido carinhoso, capaz de dedicar-se como um enfermeiro aos cuidados da esposa convalescente justamente nesse período, sem cabeça para outras matérias, é que retorna ao estudo mais sistemático da matemática e da história mundial (MUSTO, 2018, p. 101) - , o pai preocupado e bastante aberto ao diálogo - com as filhas trocou uma infinidade de cartas, tratando desde assuntos domésticos a questões teóricas e políticas - e um avô apaixonado, cuja tristeza de estar longe dos netos ele não fez questão de esconder quando tiveram de se separar devido ao retorno da filha mais velha, J enny, e do genro Charles Longuet à França, possibilitado pela anistia de1880 aos membros da Comuna de Paris de 1871 (MUSTO, 2018, pp. 28-9).

É nesse cenário de redescoberta e renovado interesse que, no ano do bicentenário de nascimento do autor de O capital, o público leitor em geral e os estudiosos da obra marxiana em particular recebem a publicação de duas grandes biografias do autor alemão, cada uma tratando de um dos dois extremos da linha evolutiva do percurso intelectual de Marx; referimo-nos à obra de Michael Heinrich (2018) e de nosso autor resenhado Marcello Musto (2018). A primeira aborda os anos anteriores à militância jornalística de Marx junto do periódico liberal Gazeta Renana, partindo do ano de nascimento, 1818, até 1841, quando Marx apresentou sua tese de doutoramento. Heinrich promete um trabalho composto por três volumes, fôlego poucas vezes visto mesmo se tratando de um autor tão biografado como Marx ${ }^{24}$. Já o livro de Musto, autor que há algum tempo vem tratando de reconstituir o itinerário biográfico-intelectual do revolucionário alemão ${ }^{25}$, de fato cumpre bem sua promessa de retratar os últimos anos de vida do Mouro, 1881-3. Ainda sobre projetos biográficos, a editora Boitempo, a mesma patrocinadora dos dois títulos anteriores e idealizadora do que ela chamou ANO MARX, promete para o final deste

24 Para um balanço (sempre parcial) das biografias sobre Marx, cf. Angelo Segrillo (2017). 25 Cf. os seguintes textos de Marcello Musto, todos publicados no Brasil: A formação da crítica de Marx à economia política: dos estudos de 1843 aos Grundrisse (2011); A vida de Marx no tempo dos Grundrisse: notas biográficas entre 1857 e 1858 (2016); A escrita de O capital: gênese e estrutura da crítica de Marx à economia política (2018b). 
ano a publicação da primeira edição da obra de José Paulo Netto, intitulada Marx: uma biografia ${ }^{26}$, que será o primeiro intento genuinamente brasileiro de biografar Marx. Enquanto aguardamos, fazemos das palavras de Wallerstein as nossas: Leiam Karl Marx! E acrescentamos ainda: e lutem! Afinal, conta-nos Musto, Marx quando indagado sobre a "finalidade última do ser" respondeu, não sem um instante de silêncio, “com um tom profundo e solene: a luta!” (2018, p. 17).

\section{Referências bibliográficas}

ÁLVARES, Lucas Parreira. O velho Marx, de Marcello Musto: por que essa biografia merece ser lida. Disponível em: <https:/ / blogdaboitempo.com.br/2018/06/07/ o-velho-marx-demarcello-musto-por-que-essa-biografia-merece-ser-lida/ \#prettyPhoto>, acessado em 10 ago. 2018.

BERTELLI, Antonio Roberto. "Uma introdução polêmica”. In: MARX, Karl. As lutas de classes na França (1848-1850). São Paulo: Global, 1986. CERQUEIRA, Hugo E. A. da Gama. Breve história da edição crítica das obras de Karl Marx. Revista Economia Política, São Paulo, v. XXXIV, n. 4, pp. 825-44, out./dez. 2015.

CHASIN, J. Textos sobre política. Revista Ensaios Ad Hominen, São Paulo, Ad Hominem, n. 1, t. III, 1999.

. A miséria brasileira, 1964-1984: do golpe militar à crise social. Santo André: Ad Hominem, 2000.

. Marx: estatuto ontológico e resolução metodológica. São Paulo:

Boitempo, 2009.

EAGLETON, Terry. Why Marx was right. Londres: Yale University Press, 2011.

ENGELS, Friedrich. "Introdução". In: MARX, Karl. As lutas de classes na França (1848-1850). São Paulo: Global, 1986.

FERNANDES, Rubem César (Org.). Dilemas do socialismo: a controvérsia entre Marx, Engels e os populistas russos. Trad. Lúcio F. R. Almeida e Rubem César Fernandes. Rio de J aneiro: Paz e Terra, 1982.

GALHARDO, Ricardo. Lula: crise é tsunami nos EUA e, se chegar ao Brasil, será "marolinha". O Globo, Rio de J aneiro, 4 out. 2008. Disponível em: <https://oglobo.globo.com/ economia/lula-crise-tsunami-nos-eua-sechegar-ao-brasil-sera-marolinha-3827410>, acessado em 10 ago. 2018.

HEINRICH, Michael. As possibilidades da escrita biográfica hoje: sobre a metodologia em uma biografia de Marx. In: . Karl Marx e o

26 Cf. <https:// www.boitempoeditorial.com.br/noticia/ novidade-2/vem-ai-108>, acessado em 8 abr. 2018. 
nascimento da sociedade moderna: biografia e desenvolvimento de sua obra v. I: 1818-1841. Trad. Cláudio Cardinali. São Paulo: Boitempo, 2018, pp. 399-419.

- Karl Marx e o nascimento da sociedade moderna: biografia e desenvolvimento de sua obra, v. I: 1818-1841. Trad. Cláudio Cardinali. São Paulo: Boitempo, 2018.

HOBSBAWM, Eric. A fortuna das edições de Marx e Engels. In.:

(Org.). História do marxismo v. I: o marxismo no tempo de Marx. Trad. Carlos Nelson Coutinho e Nemásio Salles. Rio de J aneiro: Paz e Terra, 1983, pp. 423-43.

HUBMANN, Gerald. Da política à filologia: a Marx-Engels Gesamtausgabe. Revista Crítica Marxista, Campinas, n. 34, pp. 33-49, 2012.

LÉVI-STRAUSS, Claude. Antropologia estrutural dois. Trad. Beatriz Perrone-Moisés. São Paulo: Ubu Editora, 2017.

MARTINS, Maurício Vieira. Sobre a nova edição da obra de Marx e Engels: só a filologia salva. Revista Marx e o Marxismo, Niterói, v. I, n. 1, pp. 13543, 2013.

MARX, Karl. Brief an den Vater (10. November 1837). In: MARX, Karl; ENGELS, Friedrich. Werke 40. Berlim: Dietz, 1968.

1986.

. As lutas de classes na França (1848-1850). São Paulo: Global,

. Crítica da filosofia do direito de Hegel. Trad. Rubens Enderle e Leonardo de Deus. São Paulo: Boitempo, 2010.

MARXHAUSEN, Thomas. História crítica das Obras completas de Marx e Engels (MEGA). Trad. Nélio Schneider. Revista Crítica Marxista, São Paulo, n. 39, pp. 95-124, 2014.

MUSTO, Marcello. A formação da crítica de Marx à economia política: dos estudos de 1843 aos Grundrisse. Revista Crítica Marxista, n. 33, pp. 3165, 2011.

A vida de Marx no tempo dos Grundrisse: notas biográficas entre 1857 e 1858. Revista de Políticas Públicas, São Luís, v. XX, n. 2, pp. 739-58, 2016.

. O velho Marx: uma biografia de seus últimos anos (1881-1883).

Trad. Rubens Enderle. São Paulo: Boitempo, 2018a.

- A escrita de O capital: gênese e estrutura da crítica de Marx à economia política. Trad. Murilo Leite e Carolina Peters. Verinotio Revista on-line de Filosofia e Ciências Humanas, Rio das Ostras, v. 24, n. 1, pp. 23-47, abr./2018b.

PIKETTY, Thomas. Le capital au XXIe siècle. Paris: Éditions du Seuil, 2013. 
SEGRILLO, Angelo. Karl Marx: um balanço biográfico. Estudos IberoAmericanos, Porto Alegre, v. XLIII, n. 3, pp. 601-11, set./ dez. 2017.

SHANIN, Teodor. Marx tardio e a via russa: Marx e as periferias do capitalismo. Trad. Laboratório de Estudos de Movimentos Sociais e Territorialidades da Universidade Federal Fluminense (Lemto - UFF). São Paulo: Expressão Popular, 2017.

THE NEW YORK TIMES. Was Marx Right., Nova York, 30 mar. 2014. The opinion pages: Room for debate. Disponível em: <https:// www.nytimes.com/ roomfordebate/ 2014/03/30/ was-marxright>, acessado em 10 ago. 2018.

WALLERSTEIN, Immanuel. "Leiam Karl Marx!". Musto entrevista Wallerstein. Disponível em: $<$ \ttps:/ / blogdaboitempo.com.br/ 2018/ 05/ 09/ leiam-karl-marx-mustoentrevista-wallerstein/ >, acessado em 10 ago. 2018.

Como citar:

PEREIRA, Murilo Leite. A marxologia vive em "O velho Marx": por que ler Marx 200 anos depois do seu nascimento? Verinotio - Revista on-line de Filosofia e Ciências Humanas, Rio das Ostras, v. 24, n. 2, pp. 241-252, nov. 2018.

Data de envio: 15 ago. 2018

Data de aceite: 19 set. 2018 